\title{
Effect of Huaier On the Proliferation of Mesangial Cells in Anti-Thy-1 Nephritis
}

\author{
Jiuxu Bai Wenjia Geng Yan Mei Lingling Wu Shuwei Duan Zheyi Dong \\ Bo Fu Yong Wang Fei Zhu Guangyan Cai Zhe Feng Shupeng Lin \\ Xiangmei Chen
}

Department of Nephrology, Chinese PLA General Hospital, Chinese PLA Institute of Nephrology, State Key Laboratory of Kidney Diseases, National Clinical Research Center for Kidney Diseases, Beijing,

People's Republic of China

\section{Key Words}

Huaier • Mesangial proliferative glomerulonephritis • Thy-1 nephritis • Mxi-1

\begin{abstract}
Background/Aims: To determine whether an aqueous extract of Trametes robiniophila Murr. (Huaier) suppresses anti-Thy-1 mesangial proliferative glomerulonephritis (MsPGN) in vivo and platelet-derived growth factor (PDGF)-BB-induced mesangial cell proliferation in vitro. Methods: Male Wistar rats were randomly categorized into 5 groups: Sham, Thy-1, and 3 Huaier-treated groups (low, medium, and high dose). Two weeks after treatment, urinary proteins were quantified and renal pathological changes were examined. MAX interactor 1 (Mxi-1) and proliferating cell nuclear antigen (PCNA) expression levels in isolated glomeruli, rat mesangial cell viability, cell-cycle distribution, and cell-cycle pathways were assessed. Results: Huaier diminished the proliferative damages and urinary protein secretion in Thy1 rats. PCNA was downregulated, whereas Mxi-1 was upregulated in the isolated glomeruli of Huaier-treated groups compared with the Thy- 1 group. Huaier inhibited PDGF-BBstimulated proliferation of rat mesangial cells in a time- and dose-dependent manner $(50 \%$ inhibitory concentration $=6.19 \mathrm{mg} / \mathrm{mL}$ ) and induced $\mathrm{G} 2$ cell-cycle arrest. Cell-cycle pathway proteins were downregulated, whereas Mxi-1 was upregulated in Huaier-treated mesangial cells compared with PDGF-BB-stimulated cells. Conclusion: Huaier reduces urinary protein excretion and relieves hyperplasia in mesangial cells in anti-Thy-1 MsPGN as well as inhibits PDGF-BB-stimulated proliferation and DNA synthesis of rat mesangial cells in vitro, suggesting its novel therapeutic potential in MsPGN.
\end{abstract}

\section{Introduction}

Mesangial proliferative glomerulonephritis (MsPGN) is characterized by the proliferation of mesangial cells and deposition of extracellular matrix proteins. Mesangial

J. Bai and W. Geng contributed equally to this work

Xiangmei Chen,

Shupeng Lin, and Wenjia Geng

KARGER
Department of Nephrology, Chinese PLA General Hospital, Chinese PLA Institute of

Nephrology, State Key Laboratory of Kidney Diseases, National Clinical Research Center for Kidney Diseases, 28 Fuxing Road, Beijing, (P.R. China)

E-Mail xmchen301@126.com/linshupeng301@126.com/angle11023@163.com 
cell proliferation plays an important role in progressive glomerular injury that leads to glomerular sclerosis [1]. Although MsPGN is a major cause of end-stage renal failure in many countries, its underlying mechanisms are not fully understood [2, 3]. MsPGN is of two types: IgA nephropathy and non-IgA nephropathy. However, there is currently no effective therapeutic drug to treat MsPGN. Pharmacological interventions that can inhibit inflammation, proliferation of mesangial cells, and matrix deposition may be beneficial to retard the progression of glomerulonephritis [4].

Trametes robiniophila Murr. (Huaier) is a sandy beige mushroom found on the trunks of trees such as Sophora japonica, belonging to Class Hymenomycetes, Phylum Basidiomycota. This fungus has antitumor and immunomodulatory activities and has been used in traditional Chinese Medicine for approximately 1600 years [5]. Its anticancer mechanisms include inhibition of cell growth and tumor-induced angiogenesis and inactivation of epithelialmesenchymal transition [6-8]. However, the effects of Huaier in MsPGN are thus far unknown.

Therefore, the principal aim of our study was to determine whether MsPGN can be effectively treated by Huaier in an experimental model and to investigate its underlying mechanisms of action.

\section{Materials and Methods}

\section{Induction of Anti-Thy-1 Glomerulonephritis and Experimental Design}

Eight-week-old male Wistar rats weighing 180-220 g were purchased from Beijing Vital River Laboratory Animal Technology Co., Ltd., and bred at the experimental animal center of the People's Liberation Army General Hospital under the following conditions: temperature, $22 \pm 2^{\circ} \mathrm{C}$ and humidity, 50 $\pm 20 \%$. All animal experiments were performed in accordance with the provisions of Experimental Animal Committee of the People's Liberation Army General Hospital.

The rats were randomly categorized into five groups, with 15 rats in each group: (1) Sham group, (2) Thy-1 group, (3) anti-Thy-1 nephritis model + low dose of Huaier given by gavage once a day with Huaier at a gavage dose of $1 \mathrm{mg} / \mathrm{kg}$ body weight (HRL group), (4) anti-Thy-1 nephritis model + medium dose of Huaier given by gavage once a day with Huaier at a gavage dose of $5 \mathrm{mg} / \mathrm{kg}$ body weight (HRM group), and (5) antiThy-1 nephritis model + high dose of Huaier given by gavage once a day with Huaier at a gavage dose of 10 $\mathrm{mg} / \mathrm{kg}$ body weight (HRH group).

The Sham group received $0.2 \mathrm{~mL}$ of $1 \times$ phosphate-buffered saline (PBS; pH 7.4) on Day 0 . The Thy-1 group received an intravenous injection of monoclonal anti-Thy 1 antibody $(2.5 \mathrm{mg} / \mathrm{kg})$ produced by OX-7 cells diluted in $0.9 \%$ saline (via tail veins) on Day 0 and were treated with vehicle from Day -7 to Day 7 . The HRL, HRM, and HRH groups were treated with the same dose of anti-Thy- 1 antibody as the Thy- 1 group, and the Huaier was dissolved in water daily from Day -7 to Day 7 . Electuary ointment of Huaier was provided by Gaitianli Medicine Co. Ltd. (Jiangsu, China). At $24 \mathrm{~h}$, urine samples were collected, and the protein level was measured daily. In addition, the blood urea nitrogen and creatinine levels were quantified and the serum creatinine concentration was measured. In each group, 5 rats were sacrificed on Days 1, 3 and 7.

\section{Pathological Analyses}

Tissues from the kidneys of rats in each group were fixed in $4 \%$ paraformaldehyde. Deparaffinized sections were stained with Periodic Acid-Schiff to examine the pathological changes under light microscopy. The degree of renal impairment was semi-quantitatively and double-blindly scored by two pathologists following a published scoring system [9]. We randomly selected 10 separate fields for each specimen to evaluate the lesions (400× magnification) and averaged the values for the histological score.

\section{Immunohistochemical Analysis}

Routine histological paraffin sections were cut (3-4- $\mu \mathrm{m}$ thick) and mounted on poly-L-lysine-coated slides. The sections were deparaffinized in xylene and rehydrated in alcohol, following which they were treated with 3\% hydrogen peroxide to quench the endogenous peroxide activity. Thereafter, the sections were heated in a microwave oven for $10 \mathrm{~min}$ in sodium citrate buffer ( $\mathrm{pH} 6.0)$ and incubated with $1.5 \%$ normal goat serum for $30 \mathrm{~min}$, followed by overnight incubation with proliferating cell nuclear antigen 


\section{Cellular Physiology Cell Physiol Biochem 2017;42:2441-2452 \\ \begin{tabular}{ll|l} 
and Biochemistry 10.1159/000480198 & $\begin{array}{l}\text { C } 2017 \text { The Author(s). Published by S. Karger AG, Basel } \\
\text { www.karger.com/cpb }\end{array}$ \\
\hline
\end{tabular}}

Bai et al.: Effect of Huaier in MsPGN

(PCNA) antibody (Abcam, Cambridge, MA, USA). After removal of the unbound primary antibody and rinsing with PBS, the sections were incubated with a biotinylated secondary antibody for 60 min at room temperature. Subsequently, the sections were rinsed and incubated with avidin-biotinylated horseradish peroxidase (Vectastain Elite ABC kit, Vector Laboratories, USA) for $60 \mathrm{~min}$. Thereafter, the sections were and incubated with 3, 3-diaminobenzidine tetrahydrochloride for $10 \mathrm{~min}$ as a substrate chromogen solution to produce a brown color and counterstained with hematoxylin. To quantify the proliferating cells in the glomeruli, 30 glomeruli per cross-section were counted to identify cells positive for PCNA from each biopsy at each time point. In addition, the glomerular PCNA-positive cells were identified under high-power $(\times 400)$ light microscopy in a blinded fashion by two independent pathologists. The mean values of the number of proliferating (PCNA-positive) cells per biopsy were calculated. The PCNA labeling index was calculated as the number of PCNA-positive cells to the total number of glomerular cells. For immunofluorescence staining, glomerular deposition of the anti-Thy-1 antibody in kidney samples from rats with anti-Thy-1 nephritis on Day 1 was detected using Alexa Fluor 555 donkey anti-mouse IgG (H+L) (Invitrogen, Carlsbad, CA, USA).

\section{Cell Culture and Transfection}

A rat mesangial cell line was purchased from the American Type Culture Collection (ATCC). Cells were cultured in RPMI 1640 medium (Gibco, USA) containing $10 \%$ fetal calf serum (Hyclone, Canada) at $37^{\circ} \mathrm{C}$ in a $5 \% \mathrm{CO}_{2}$ atmosphere. Mxi-1 siRNA [10] (GenePharma, Shanghai, China) (100 nM) was transfected into mesangial cells for $48 \mathrm{~h}$ using jetPRIME ${ }^{\mathrm{TM}}$ (Polyplus-transfection, France) according to the protocol supplied by the manufacturer.

\section{Cell-viability Assay}

Cells in the logarithmic phase were selected, and the cell concentration was adjusted to $1 \times 10^{4} /$ $\mathrm{mL}$. Cells were seeded in a 96-well plate and cultured for $24 \mathrm{~h}$ until they were completely adherent. With serum-free 1640 culture medium, the cells were synchronized for $12 \mathrm{~h}$. After Platelet-Derived Growth Factor-BB (PDGF-BB, Sigma, USA) (30 ng/mL) [11] or Huaier treatment, a Cell Counting Kit-8 (CCK-8, Dojindo, Japan) was used to detect the proliferation of mesangial cells at 12,24 , and $48 \mathrm{~h}$, and the number of viable cells was measured by recording the optical density at $450 \mathrm{~nm}$ and generating growth curves. All experiments were performed in triplicate.

Cell-cycle Analysis

A total of $10^{5}$ cells/well were seeded in 6 -well plates and starved in serum-free 1640 medium at $37^{\circ} \mathrm{C}$. After $12 \mathrm{~h}$ of starvation, the cells were treated with PDGF-BB or Huaier and complete medium for $48 \mathrm{~h}$. The cells were trypsinized, washed with cold PBS, and stained using the Cycletest Plus DNA Reagent Kit (BD Biosciences, USA) according to the manufacturer's instructions. The cell cycle was analyzed by flow cytometry (Beckman Coulter, USA). All experiments were independently performed in triplicate.

\section{5-Ethynyl-2'-deoxyuridine (EdU) Assay}

Cells were seeded into 12 -well culture plates at a density of $1.0 \times 10^{4}$ cells/well and incubated for $24 \mathrm{~h}$ in RPMI 1640 medium. After $12 \mathrm{~h}$ of starvation, the cells were treated with PDGF-BB or Huaier and complete medium for $48 \mathrm{~h}$. After $48 \mathrm{~h}$ of stimulation, cell proliferation was determined using an EdU immunofluorescence assay according to the manufacturer's instructions (Life tech, USA). EdU-positive cells were quantified from 10 images, and the images collected were analyzed by Image-Pro Plus 6.0 (Media Cybernetics, Rockville, MD, USA).

\section{Isolation of Glomeruli}

The kidney capsules were removed, and cortices were dissected from each kidney. The cortical sections were minced with a razor blade and subsequently pressed through a $180-\mu \mathrm{m}$ pore sieve. Thereafter, the sections were rinsed through successive sieves (pore size, 104-37 $\mu \mathrm{m}$ ) using ice-cold PBS. Tissue containing glomeruli on the 63- $\mu \mathrm{m}$ mesh was collected, and its purity was assessed using light microscopy. Renal cortical tubules were purified from rat kidneys by using a Percoll gradient centrifugation technique [12].

Western Blot Analysis

Proteins were extracted from isolated glomeruli, tubules, or rat mesangial cells using RIPA lysis buffer (50 mM Tris-HCl, pH 7.5, $150 \mathrm{mM} \mathrm{NaCl}, 0.5 \%$ deoxycholate, $1 \%$ Nonidet P-40, $0.1 \%$ sodium dodecyl sulfate 
[SDS], $1 \mathrm{mM}$ phenyl methyl sulfonyl fluoride, and protease cocktail at $1 \mu \mathrm{g} / \mathrm{mL}$ ). Protein concentrations were determined using a BCA kit (Pierce, USA). Protein samples (50 $\mu \mathrm{g}$ per lane) were separated by $10 \%$ SDS-polyacrylamide gel electrophoresis and transferred to nitrocellulose membranes. The membranes were incubated overnight in $5 \%$ non-fat milk at $4{ }^{\circ} \mathrm{C}$, followed by incubation with primary antibodies against neutral and basic amino acid transporter (rBAT), podoplanin, PCNA, Mxi-1, cyclin B1, CDK 1, CDK 2 (Abcam), and $\beta$-actin (Sigma). After incubation of individual primary antibodies, the membrane was washed three times with Tris-buffered saline plus Tween 20, followed by incubation of secondary antibody for $1 \mathrm{~h}$. The detection of specific signals was performed using enhanced chemiluminescence (Amersham Biosciences, Little Chalfont, UK). All experiments were repeated at least three times.

\section{Statistical Analyses}

Data are reported as mean \pm standard error of mean of at least three independent experiments. Statistical significance, defined as $P<0.05$, was evaluated using one-way analysis of variance with SPSS software (version 19.0, Chicago, IL, USA). The $50 \%$ inhibitory concentration $\left(\mathrm{IC}_{50}\right)$ was calculated using Prism software version 5.0 (Graph-Pad Software, San Diego, CA).

\section{Results}

Effect of Huaier Treatment on Proteinuria and Pathological Changes in Anti-Thy-1 Nephritis

During the study course, no clinical adverse effects were observed in the study animals. The 24-h urine protein level was determined for each rat on Days 3 and 7 (Fig. 1A). Compared with the Sham group, the anti-Thy-1 group demonstrated frank proteinuria on Days 3 and 7 of nephritis. The HRM and HRH groups, in which Huaier was administered before induction of nephritis, showed a significant reduction in the urinary protein levels at $24 \mathrm{~h}(P<0.05)$. Pathological analysis revealed that the renal cortical tissue from anti-Thy- 1 nephritic rats showed prominent mesangial hypercellularity and glomerular sclerosis on Day 7 of nephritis. In anti-Thy- 1 nephritic rats treated with HRM and HRH, but not those treated with HRL, the histological changes were significantly attenuated (Fig. 1B, 1C). Furthermore, HRM and HRH treatment significantly reduced the total injury score of the glomeruli $(P<0.05$; Fig. 1D). We examined the change in body weight of animals treated with drugs in 2 weeks to show the safety of Huaier use and found no difference among the anti-Thy-1, HRL, HRM, and HRH groups (Fig. 1E). The serum levels of urea nitrogen and creatinine were prone to increase in all groups (Fig. 1E). However, there were no significant differences among these groups. To confirm that Huaier does not affect glomerular deposition of the anti-Thy-1 antibody, we examined the degree of glomerular deposition of anti-Thy- 1 antibody by using kidney samples from rats with anti-Thy-1 nephritis on Day 1 . The results showed no difference in glomerular deposition of the anti-Thy-1 antibody among the groups analyzed (Fig. 1F). These findings suggest an anti-proteinuric effect of Huaier treatment against anti-Thy-1 nephritis.

\section{Effects of Huaier on Mesangial Cell Proliferation in Anti-Thy-1 Nephritis}

The anti-Thy-1 group was characterized by mesangial cell proliferation and matrix expansion on Day 7. Total glomerular cell numbers and the number of cells positive for PCNA markers were compared between anti-Thy-1 rats and Sham rats (Fig. 2A-C). Administration of HRM and HRH reduced the severity of MsPGN. The number of PCNA-positive cells was significantly reduced by HRM and HRH treatment $(P<0.05)$, demonstrating that Huaier inhibited mesangial cell proliferation in an anti-Thy- 1 model. Podoplanin is specifically expressed in glomeruli $[13,14]$, and rBAT is specifically expressed in tubules [15]. We assessed the expression of podoplanin and rBAT to confirm the enrichment of glomerular proteins by western blot analysis (Fig. 2D). In terms of PCNA protein expression in isolated glomeruli, western blot analysis showed that the HRM and HRH groups expressed lower levels of PCNA than the anti-Thy-1 group, consistent with the immunohistochemical results 

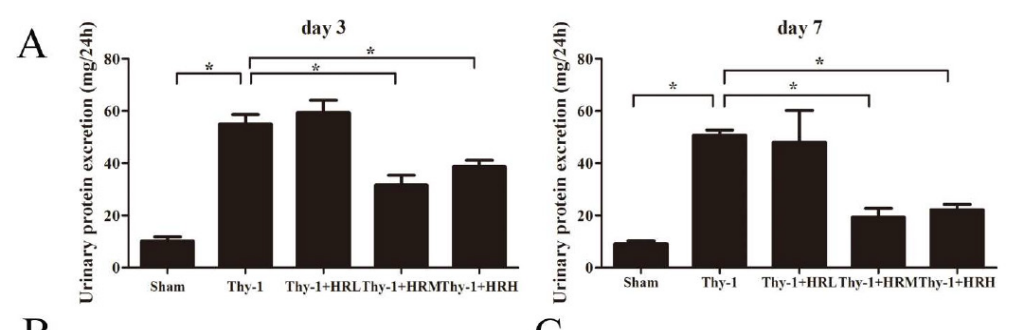

$\mathrm{B}$
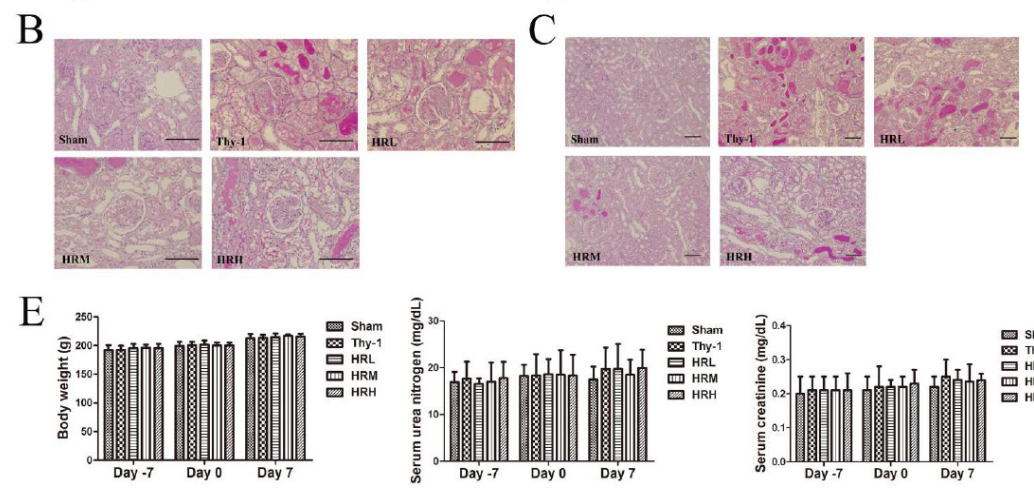

$\mathrm{D}$
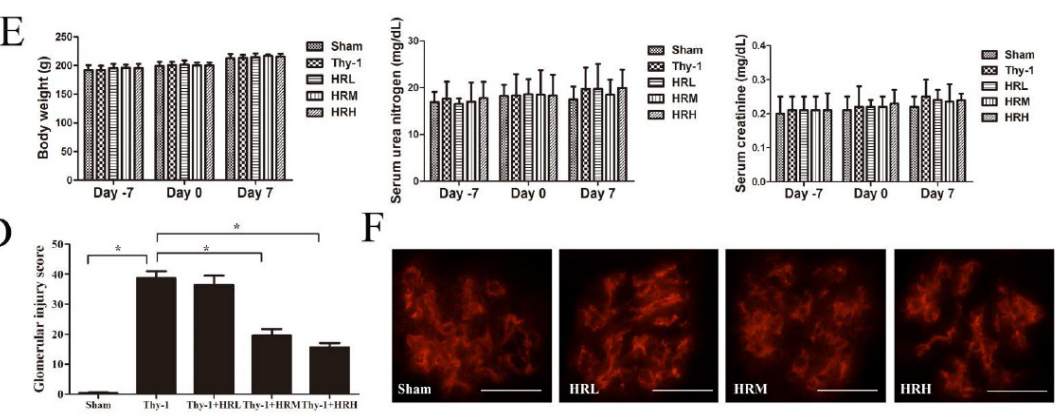

F

Fig. 1. Effect of Huaier treatment on proteinuria and pathological changes in anti-Thy-1 nephritis. (A) Twenty-four-hour urinary protein excretion on Days 3 and 7 in anti-Thy 1 nephritis rats $\left({ }^{*} \mathrm{P}<0.05\right)$. (B) Representative images of glomeruli from vehicle- or Huaier-treated animals with Thy-1 nephritis stained with Periodic Acid-Schiff. Bars $=100 \mu \mathrm{m}$. Magnification: $\times 400$. (C) Representative images of glomeruli from vehicle- or Huaier-treated animals with Thy-1 nephritis stained with Periodic Acid-Schiff. Bars $=100 \mu \mathrm{m}$. Magnification: $\times 200$. (D) The glomerular injury score in all 5 groups $(* P<0.05)$. (E) Time course of body weight and serum concentrations of urea nitrogen and creatinine. (F) Immunofluorescence studies show the degree of glomerular deposition of anti-Thy-1 antibody from rats with anti-Thy-1 nephritis on Day 1. Deposition of anti-Thy- 1 antibody shows no change in all 4 groups. Bars $=50 \mu \mathrm{m}$. Magnification: $\times 400$. HRL, low-dose Huaier; HRM, medium-dose Huaier; HRH group, high-dose Huaier.

(Fig. 2E). Our previous study showed that Mxi1 inhibits mesangial proliferation [10]. In this study, we found that Mxi-1 expression in the anti-Thy-1 group decreased on Day 7 compared with the Sham group and increased in the HRM and HRH groups.

Effects of Huaier on the Proliferation of Mesangial Cells in vitro

A previous study showed that PDGF-BB is essential for mesangial cell proliferation preceding the development of glomerulosclerosis in experimental glomerulonephritis [16]. In our study, after confirming that mesangial cells are stimulated with PDGF-BB in vitro, we investigated the effects of Huaier on the proliferation of cells. The CCK-8 assay showed that PDGF-BB increased mesangial cell proliferation compared to the control cultures at 12, 24, and $48 \mathrm{~h}$ (Fig. 3A). However, Huaier inhibited PDGF-BB-induced proliferation of mesangial cells in a dose-dependent manner, with an $\mathrm{IC}_{50}$ of approximately $6.19 \mathrm{mg} / \mathrm{mL}(P<0.05)$ (Fig. 3A, 3B). PCNA is a cell cycle-associated nuclear protein and is used as a marker for cell proliferation. Western blot analysis showed that PCNA protein expression increased by PDGF-BB stimulation, which was reduced by Huaier treatment in mesangial cells (Fig. 3C). The EdU assays used to detect the DNA-synthesis capacity of mesangial cells (Fig. 3D) 


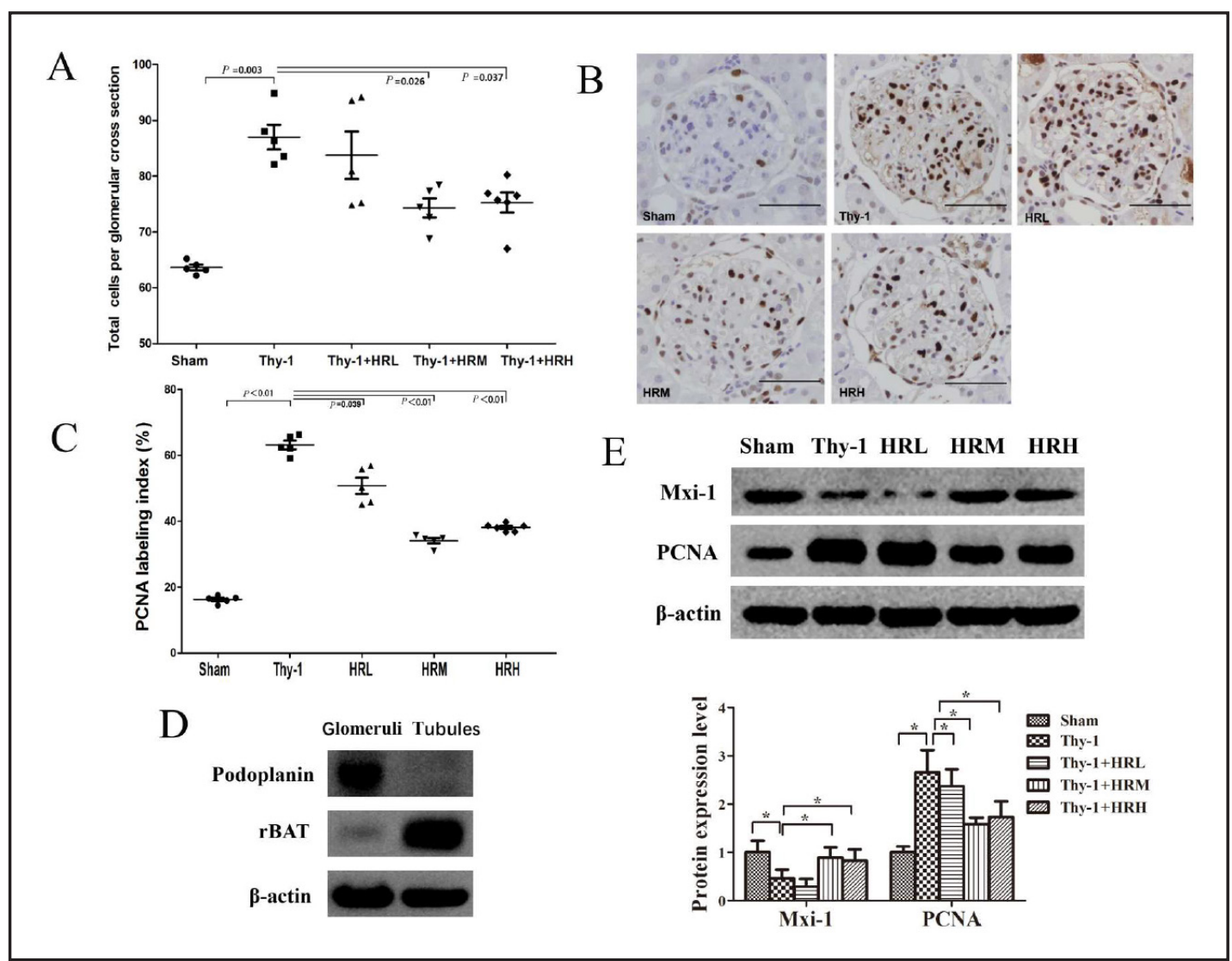

Fig. 2. Effects of Huaier on mesangial cell proliferation in anti-Thy-1 nephritis. (A) Increase in glomerular cell number with disease induction $\left({ }^{*} \mathrm{P}<0.05\right)$. (B) Representative images of kidneys immunostained for PCNA. Bars $=50 \mu \mathrm{m}$. Magnification: $\times 400$. (C) The number of PCNA-positive nuclei per glomerulus in all 5 groups $\left({ }^{*} \mathrm{P}<0.05\right)$. (D) Western blot analysis of podoplanin and rBAT protein expression in each group (glomeruli and tubules were isolated from the renal cortex). $\beta$-actin is taken as an internal reference. (E) The relative quantitation of PCNA and Mxi-1 protein expression in each group, as shown by Western blot analysis. $\beta$-actin is taken as an internal reference $\left({ }^{*} \mathrm{P}<0.05\right)$. HRL, low-dose Huaier; HRM: medium-dose Huaier; HRH group, high-dose Huaier; PCNA, proliferating cell nuclear antigen.

showed that the percentage of EdU-positive cells in the PDGF-BB group was higher than that in the control group, wherever Huaier decreased EdU-positive cells significantly compared with PDGF-BB-stimulated cells $(P<0.05$; Fig. 3E).

\section{Impact of Huaier on the Cell Cycle of Mesangial Cells}

To determine whether the anti-proliferative effect of Huaier attributes to its induction of cell-cycle arrest, we treated mesangial cells with Huaier for $48 \mathrm{~h}$ and analyzed the cellcycle distribution. Huaier treatment increased the percentage of mesangial cells in the G2/M phase $(P<0.05)$ (Fig. 4A, 4B). The effects of Huaier on the expression of cell cycle-related proteins were detected by western blot. We found that the levels of Cyclin B1, CDK 1, and CDK 2 significantly increased in the PDGF-BB group, while those of the cell cycle-related proteins significantly decreased $(P<0.05)$ in the Huaier group (Fig. $4 \mathrm{C})$.

\section{Effect of Mxi-1 on Mesangial Cells Treated with Huaier}

We studied the effect of Mxi-1 on mesangial cells treated with Huaier in vitro and explored its possible mechanisms. Mxi-1 expression was significantly downregulated in the PDGF-BB group but significantly upregulated in the Huaier group $(P<0.05)$ (Fig. 5A). Mxi- 


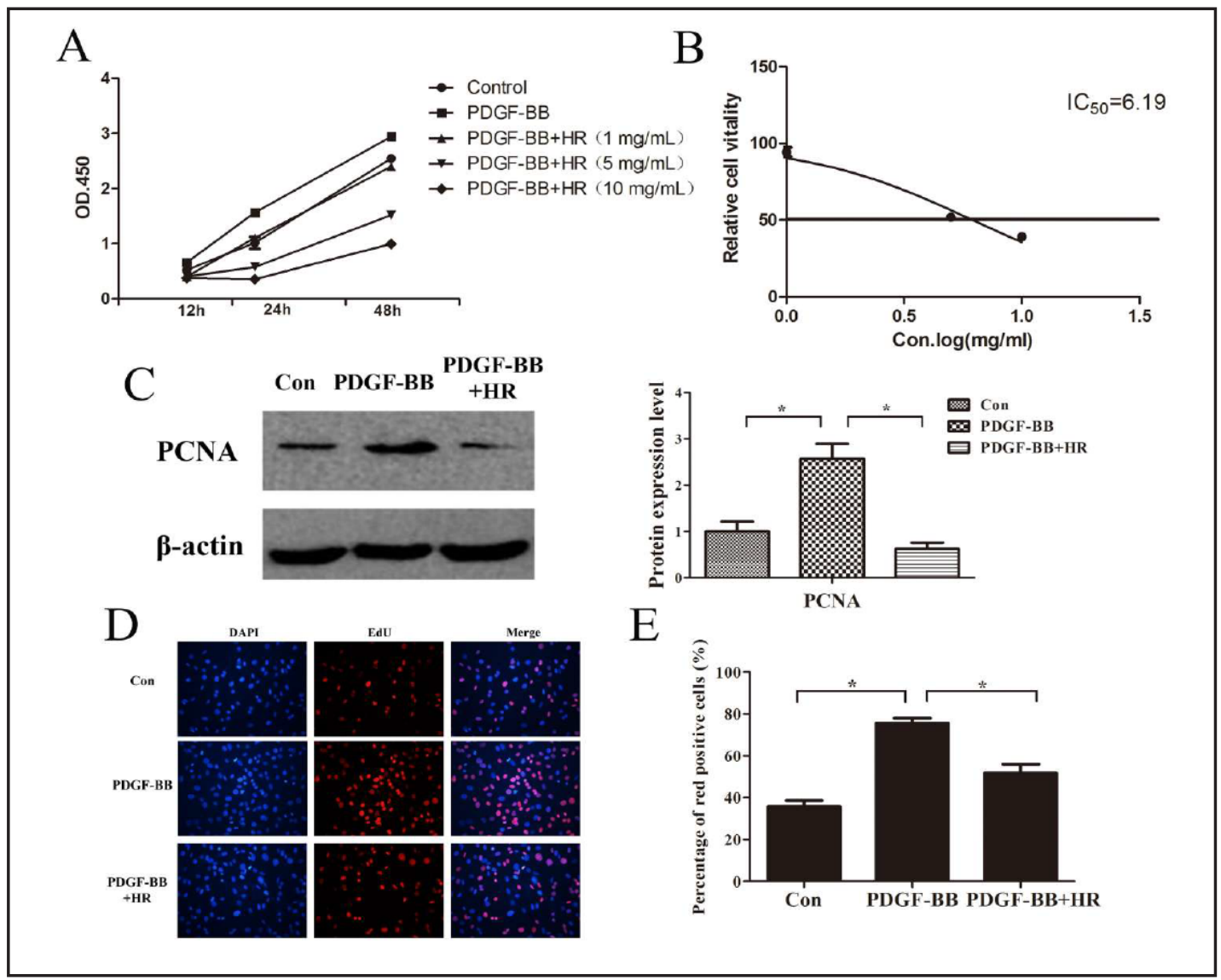

Fig. 3. Effects of Huaier on the proliferation of mesangial cells. (A) The effect of Huaier on cell viability, as measured by CCK-8 assay. (B) The 50\% inhibitory concentration ( $\mathrm{IC}_{50}$ ). (C) Western blot analysis of PCNA in mesangial cell treated with PDGF-BB and Huaier $(5 \mathrm{mg} / \mathrm{mL})$ for $48 \mathrm{~h} ; \beta$-actin serves as a loading control. The relative quantitation of PCNA protein, expressed as the ratio of PCNA $/ \beta$-actin $\left({ }^{*} \mathrm{P}<0.05\right)$. (D) DNA replication activity of mesangial cells in PDGF-BB (30 ng/mL) and Huaier ( $5 \mathrm{mg} / \mathrm{mL})$-treated groups for $48 \mathrm{~h}$, as shown by the EdU assay. (E) Percentage of EdU-positive cells in each group $\left({ }^{*} \mathrm{P}<0.05\right)$. Con, control; HR, Huaier; PDGF, platelet-derived growth factor; PCNA, proliferating cell nuclear antigen; DAPI, 4',6-diamidino-2phenylindole.

1 expression could be significantly downregulated by specific siRNA targeting Mxi-1 (Fig. 5B). The EdU assays showed that the percentage of EdU-positive cells in the Huaier group decreased as compared to the control group, wherever si-Mxi-1 increased the number of EdU-positive cells significantly $(P<0.05)$ (Fig. 5C, 5D). Western blot analysis of cell-cycle regulatory proteins showed that the expression of cyclin B1, CDK 1, and CDK 2 decreased in the Huaier group, and this decrease was attenuated by si-Mxi1 transfection $(P<0.05)$ (Fig. $5 \mathrm{E})$. Thus, Mxi-1 may play a role in inhibiting mesangial cells treated with Huaier.

\section{Discussion}

In the present study, we found that an aqueous extract of T. robiniophila Murr. (Huaier) inhibits mesangial cell proliferation in an anti-Thy-1 model of MsPG. Additionally, the antiproliferative effects of Huaier on mesangial cells were confirmed in vitro. To our knowledge, this is the first study to report that Huaier inhibits the proliferation of mesangial cells. These 


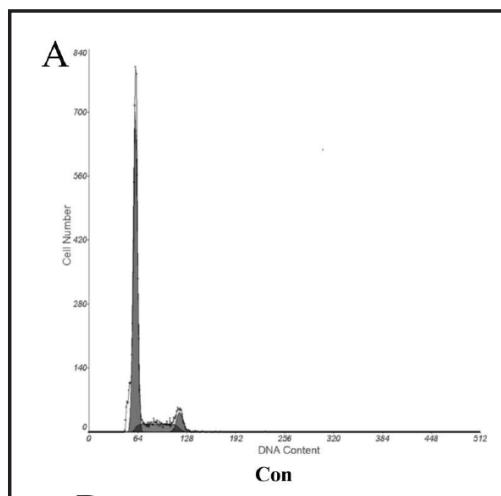

B

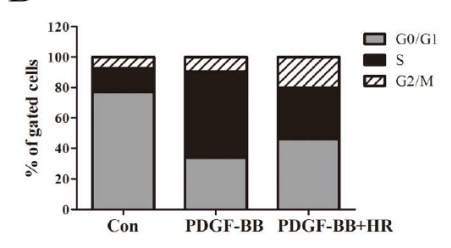

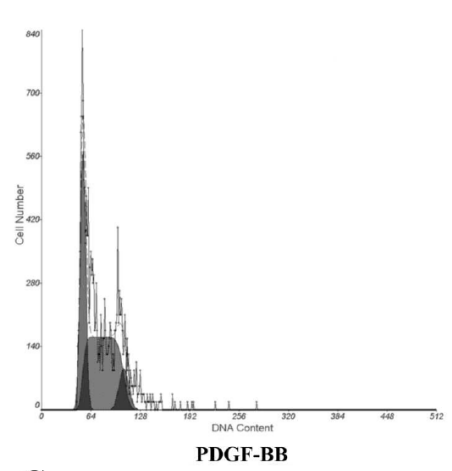

C

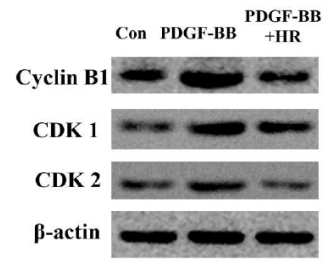

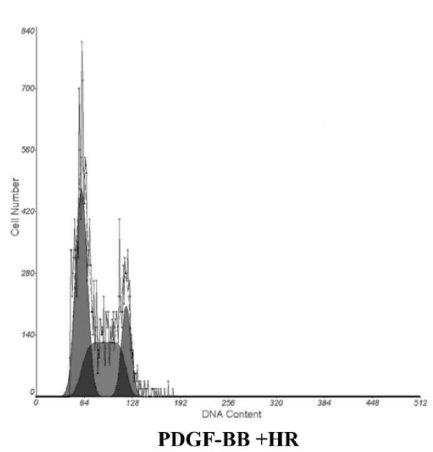

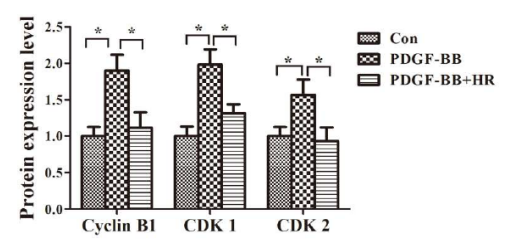

Fig. 4. Effect of Huaier on the cell cycle. (A) Mesangial cells treated with PDGF-BB (30 ng/mL) and Huaier (5 $\mathrm{mg} / \mathrm{mL}$ ) for $48 \mathrm{~h}$. Flow cytometry analysis shows that cells accumulate in the G2M phase. (B) Distribution of the cell cycle in mesangial cells. (C) The relative quantitation of cell-cycle regulatory proteins in each group, as assessed by Western blot analysis. $\beta$-actin is used as an internal reference $\left({ }^{*} \mathrm{P}<0.05\right)$. Con, control; HR, Huaier; PDGF, platelet-derived growth factor.

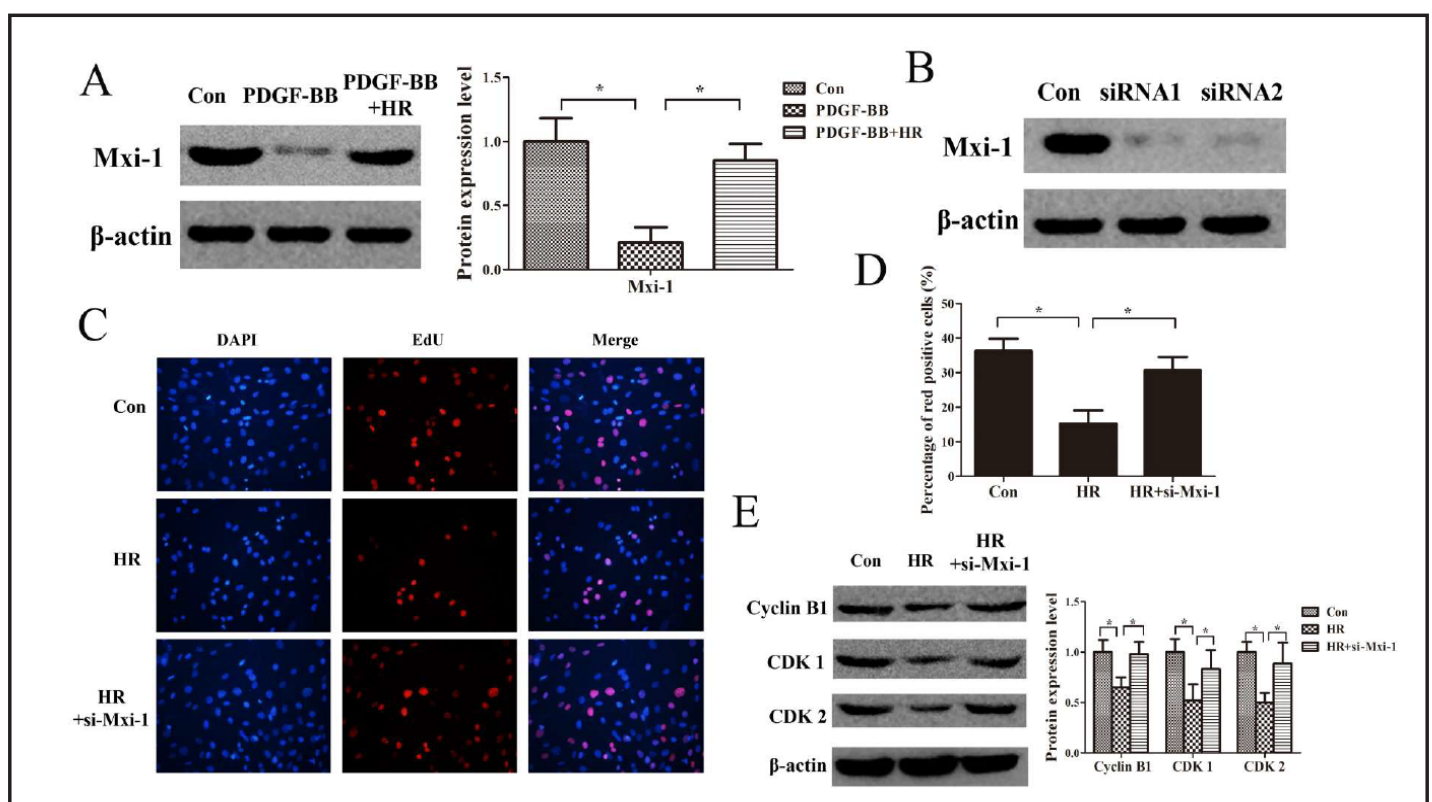

Fig. 5. Effect of Mxi-1 on mesangial cells treated with Huaier. (A) Western blot analysis of Mxi-1 in mesangial cells treated with PDGF-BB $(30 \mathrm{ng} / \mathrm{mL})$ and Huaier $(5 \mathrm{mg} / \mathrm{mL})$ for $48 \mathrm{~h}$. $\beta$-actin serves as a loading control. The relative quantitation of PCNA protein, expressed as the ratio of Mxi- $1 / \beta$-actin $\left({ }^{*} \mathrm{P}<0.05\right)$. (B) Western blot analysis of Mxi-1 protein expression after transient transfection with Mxi-1 siRNA1 and siRNA1 in mesangial cells; $\beta$-Actin is used as a loading control. (C) DNA replication activity of mesangial cells treated with Huaier $(5 \mathrm{mg} / \mathrm{mL}$ ) for $48 \mathrm{~h}$ with or without Mxi-1 siRNA transient transfection, as examined by EdU assay. (D) Percentage of EdU-positive cells in each group $\left({ }^{*} \mathrm{P}<0.05\right)$. (E) The relative quantitation of cell cycle regulatory protein expression in each group, as assessed by Western blot analysis. $\beta$-actin is taken as an internal reference $\left({ }^{*} \mathrm{P}<0.05\right)$. Con, control; HR, Huaier; PDGF, platelet-derived growth factor; DAPI, 4',6-diamidino-2-phenylindole.

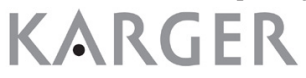


findings support a central role of Huaier in MsPGN and provide a new therapeutic strategy for its treatment.

Chronic kidney disease (CKD) is one of the most-important risk factors for cardiovascular events, induction of renal replacement therapies, and even death $[17,18]$. Among the many types of primary kidney disease, MsPGN, including IgA nephropathy, is a representative proteinuric kidney disease that leads to CKD. Anti-Thy-1 glomerulonephritis is a wellestablished nephritis model that simulates human MsPGN [19]. It is induced by the binding of anti-Thy- 1 antibody to the corresponding antigen on the membrane of mesangial cells and is marked by evident transient inflammatory glomerular lesions, mesangial cells proliferation, glomerular capillary aneurysm formation, and extracapillary proliferation, displaying substantial proteinuria during the course. Although anti-Thy-1 glomerulonephritis in rats is not a consequence of collection of abnormal IgA-containing deposits in the glomeruli, and the results obtained cannot be directly extrapolated to human IgA nephropathy, it still represents a relevant model for studying interventions directed at mesangial cell proliferation and mesangial matrix deposition [20,21].

Thy1.1 nephritis is characterized by the recruitment of inflammatory cells and consequent mesangial proliferation [22]. It was shown that patients with MsPGN have increased peripheral Th17 cells and serum or urinary IL-17 levels [23, 24], CD4 T cells and Th1 cytokines also contribute to the development of the Thy- 1 nephritis model, and the suppression of cytokine production could be a valid target for therapy [25-27]. The cell cycle protein kinase inhibitor p27kip negatively regulates the cell cycle [28]. In the normal glomerulus, p2 $7^{\text {kip } 1}$ is highly expressed to maintain a steady-state in the kidney and avoid overproliferation; its level decreases with the initiation of the proliferative response of the mesangial cells and then normalizes with the resolution of the mesangial cell proliferation [29]. A strong induction of CDK 2 kinase activity was noticed during the mesangioproliferative phase in anti-Thy $1.1 \mathrm{GN}$; mesangial cell proliferation was reduced markedly by MEK inhibition via a decrease in glomerular and renal cortical cyclin E, A and CDK 2 overexpression [30]. The antiproliferative and immunosuppressive rapamycin derivative RAD used in inflammatory renal disease has been studied to inhibit mesangial cell migration in the anti-Thy1 model through the CDK-inhibitor p27 $7^{\mathrm{KIP} 1}$ [31]. Matrix metalloproteinase inhibitors, which have antiinflammatory features, can induce cell-cycle arrest with subsequent apoptosis in mesangial cells in Thy1.1 nephritis [32]. Therefore, it may be concluded that the concept of induction of cell cycle arrest may contribute to the development of new perspectives in the therapy of inflammation in inflammatory renal disease.

The aqueous extract of Huaier mainly comprises proteoglycan, which is the main effective ingredient responsible for the anticancer and immunomodulatory effects of Huaier [33]. The proteoglycan contains $41.53 \%$ polysaccharides, $12.93 \%$ amino acids, and $8.72 \%$ water [8]. Huaier has been used as an anti-carcinogenic medicine for the treatment of cancer, with satisfactory results. The anti-tumor mechanism of Huaier may be associated with the inhibition of endothelial cell proliferation, interference with tumor angiogenesis, and suppression of tumor cell proliferation [7]. The antiproliferative effect of Huaier in cancer cells has been well studied. MsPGN including, IgA nephropathy, is mainly characterized by the proliferation of mesangial cells. Huai Qi Huang $(\mathrm{HQH})$, a compound Chinese herbal medicine that contains Huaier, wolfberry fruit, and Polygonatum, can ameliorate proteinuria and hematuria in cases of mild IgA nephropathy [34]. HQH significantly reduces proteinuria and ameliorates tubulointerstitial damage in adriamycin nephrosis in rats [35]. The main ingredient of Huaiqihuang is Huaier, and no studies have thus far assessed the effect of Huaier in MsPGN. Therefore, we chose mesangial cells and experimental mesangial proliferative glomerulonephritis as a model to determine the potential of Huaier in MsPGN treatment. Our study indicated that Huaier treatment effectively reduces the number of PCNA-positive glomerular cells and alleviates proteinuria. This is the first study to investigate the antiproliferation effect of Huaier in an experimental MsPGN model.

The regulatory mechanism of mesangial proliferation in MsPGN is complex [36-39]. PDGF has been widely implicated in the pathogenesis of progressive renal injury in both 


\section{Cellular Physiology Cell Physiol Biochem 2017;42:2441-2452

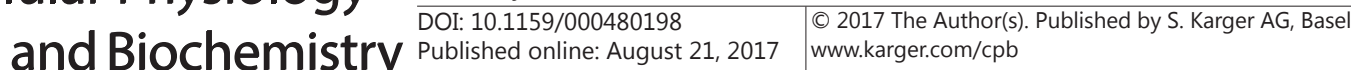 \\ Bai et al.: Effect of Huaier in MsPGN}

experimental models and human disease [40, 41]. It is known to participate in either mesangial cell proliferation or mesangial matrix expansion that follows mesangial cell injury with anti-Thy-1 antibody and plays a central role in proliferative glomerular disease [42]. Therefore, specific inhibition of the mitogenic actions of PDGF is a major target for MsPGN therapy. Several compounds have been reported to inhibit PDGF-stimulated proliferation of mesangial cells [43]. Our data showed that administration of Huaier, which potently inhibited PDGF-BB-induced proliferation of mesangial cells in vitro, markedly suppressed mesangial cell proliferation.

We used flow cytometry to evaluate the effect of Huaier on the cell cycle and found that it can extend the G2 phase and inhibit cell proliferation by regulating cell cycle proteins. Huaier has been reported to cause G2/M cell-cycle arrest in human cervical cancer cells [44]. Mxi1, a member of the Mad family of transcription factors, has a suppressive effect in human glioblastomas and correlates with cell-cycle arrest [45]. Our previous studies have shown that Mxi1 inhibits the proliferation of mesangial cells, and overexpression of Mxi1 has been shown to inhibit the expression of cyclin B1, thereby inducing a G2/M block [10]. In our study, Mxi1 expression increased with Huaier treatment in anti-Thy-1 rats in vivo and in mesangial cells in vitro. Furthermore, si-Mxi1 attenuated Huaier-induced inhibition of mesangial cell proliferation. We speculate that Huaier inhibits the proliferation of mesangial cells by upregulating Mxi1 expression. Further studies are needed to clarify the mechanisms of the suppressive effect of Huaier.

\section{Conclusion}

Huaier potently inhibits PDGF-BB-induced proliferation of mesangial cells in vitro and mesangial cell proliferation and extracellular matrix expansion in an anti-Thy 1 glomerulonephritis model in vivo. Our results suggest a novel therapeutic potential for MsPGN.

\section{Acknowledgements}

This work was supported by grants from the National Key Research and Development Program of China [grant numbers 2016YFC0906200], the National Key Technology R\&D Program [grant numbers 2013BAI09B05, 2015BAI12B06], the National Natural Sciences Foundation of China [grant number 81330019], the Science and Technology Project of Beijing, China [grant number D131100004713003], and the China Postdoctoral Science Foundation [grant number 2013M542447].

\section{Disclosure Statement}

The authors declare no conflicts of interest.

\section{References}

1 Striker LJ, Doi T, Elliot S, Striker GE: The contribution of glomerular mesangial cells to progressive glomerulosclerosis. Semin Nephrol 1989;9:318-328.

- Lai KN, Wang AY: IgA nephropathy: common nephritis leading to end-stage renal failure. Int J Artif Organs 1994;17:457-460.

-3 Zhang A, Han Y, Wang B, Li S, Gan W: Beyond Gap Junction Channel Function: the Expression of Cx43 Contributes to Aldosterone-Induced Mesangial Cell Proliferation via the ERK1/2 and PKC Pathways. Cell Physiol Biochem 2015;36:1210-1222.

-4 Chiang CK, Sheu ML, Hung KY, Wu KD, Liu SH: Honokiol, a small molecular weight natural product, alleviates experimental mesangial proliferative glomerulonephritis. Kidney Int 2006;70:682-689. 


\section{Cellular Physiology Cell Physiol Biochem 2017;42:2441-2452

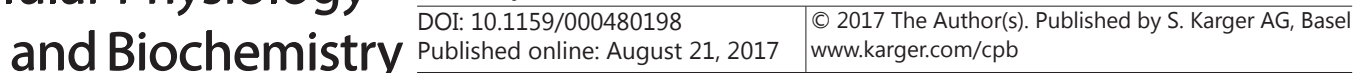

Bai et al.: Effect of Huaier in MsPGN

-5 Sun Y, Sun T, Wang F, Zhang J, Li C, Chen X, Li Q, Sun S: A polysaccharide from the fungi of Huaier exhibits anti-tumor potential and immunomodulatory effects. Carbohydrate Polymers 2013;92:577-582.

6 Zheng J, Li C, Wu X, Liu M, Sun X, Yang Y, Hao M, Sheng S, Sun Y, Zhang H: Huaier polysaccharides suppresses hepatocarcinoma MHCC97-H cell metastasis via inactivation of EMT and AEG-1 pathway. Int J Biol Macromol 2014;64:106-110.

7 Wang X, Zhang N, Huo Q, Yang Q: Anti-angiogenic and antitumor activities of Huaier aqueous extract. Oncol Rep 2012;28:1167-1175.

-8 Zhang N, Kong X, Yan S, Yuan C, Yang Q: Huaier aqueous extract inhibits proliferation of breast cancer cells by inducing apoptosis. Cancer Sci 2010;101:2375-2383.

-9 Cove-Smith A, Mulgrew CJ, Rudyk O, Dutt N, Mclatchie LM, Shattock MJ, Hendry BM: Anti-proliferative actions of T-type calcium channel inhibition in Thy1 nephritis. Am J Pathol 2013;183:391-401.

10 Liu X, Lv Y, Xie Y, Hong Q Cai G, Zhang S, Liu W, Chen X: Change of MAX interactor 1 expression in an antiThy1 nephritis model and its effect on mesangial cell proliferation. Cell Physiol Biochem 2011;27:391-400.

11 Kawano H, Kim S, Ohta K, Nakao T, Miyazaki H, Nakatani T, Iwao H: Differential contribution of three mitogen-activated protein kinases to PDGF-BB-induced mesangial cell proliferation and gene expression. J Am Soc Nephrol 2003;14:584-592.

12 Vinay P, Gougoux A, Lemieux G: Isolation of a pure suspension of rat proximal tubules. Am J Physiol 1981;241:403-411.

-13 Breitenedergeleff S, Matsui K, Soleiman A, Meraner P, Poczewski H, Kalt R, Schaffner G, Kerjaschki D: Podoplanin, novel 43-kd membrane protein of glomerular epithelial cells, is down-regulated in puromycin nephrosis. Am J Pathol 1997;151:1141-1152.

-14 Kohda Y, Murakami H, Moe OW, Star RA: Analysis of segmental renal gene expression by laser capture microdissection. Kidney Int 2000;57:321-331.

-15 Furriols M, Chillarón J, Mora C, Castelló A, Bertran J, Camps M, Testar X, Vilaró S, Zorzano A, Palacín M: rBAT, related to L-cysteine transport, is localized to the microvilli of proximal straight tubules, and its expression is regulated in kidney by development. J Biol Chem 1993;268:27060-27068.

16 Ostendorf T, Kunter U, Gröne HJ, Bahlmann F, Kawachi H, Shimizu F, Koch KM, Janjic N, Floege J: Specific antagonism of PDGF prevents renal scarring in experimental glomerulonephritis. J Am Soc Nephrol 2001;12:909-918.

17 Sarafidis PA, Bakris GL: Cardiovascular disease in CKD in 2014: New insights into cardiovascular risk factors and outcomes. Nature Reviews Nephrology 2015;11:70-72.

18 Go AS, Chertow GM, Fan D, Mcculloch CE, Hsu CY: Chronic kidney disease and the risks of death, cardiovascular events, and hospitalization. N Engl J Med 2004;351:1296-1305.

19 Bagchus WM: Glomerulonephritis induced by monoclonal anti-Thy1.1 antibodies. Plasma Gelsolin Promotes 1986;55:680-687.

20 Jefferson JA, Johnson RJ: Experimental mesangial proliferative glomerulonephritis (the anti-Thy-1.1 model). Journal of Nephrology 1999;12:297-307.

-21 Ishizuka S, Cunard R, Poucell-Hatton S, Wead L, Lortie M, Thomson SC, Gabbai FB, Satriano J, Blantz RC: Agmatine inhibits cell proliferation and improves renal function in anti-Thy-1 glomerulonephritis. J Am Soc Nephrol 2000;11:2256-2264.

$\checkmark 22$ Yamamoto T, Yamamoto K, Kawasaki K, Yaoita E, Shimizu F, Kihara I: Immunoelectron microscopic demonstration of Thy-1 antigen on the surfaces of mesangial cells in the rat glomerulus. Nephron 1986;43:293-298.

-23 Lin FJ, Jiang GR, Shan JP, Zhu C, Zou J, Wu XR: Imbalance of regulatory T cells to Th17 cells in IgA nephropathy. Scand J Clin Lab Invest 2012;72:221-229.

24 Matsumoto K, Kanmatsuse K: Increased urinary excretion of interleukin-17 in nephrotic patients. Nephron 2002;91:243-249.

25 Ikezumi Y, Kawachi H, Toyabe S, Uchiyama M, Shimizu F: An anti-CD5 monoclonal antibody ameliorates proteinuria and glomerular lesions in rat mesangioproliferative glomerulonephritis. Kidney Int 2000;58:100-114.

26 Ikezumi Y, Kanno K, Koike H, Tomita M, Uchiyama M, Shimizu F, Kawachi H: FK506 ameliorates proteinuria and glomerular lesions induced by anti-Thy 1.1 monoclonal antibody 1-22-3. Kidney Int 2002;61:13391350 . 


\section{Cellular Physiology Cell Physiol Biochem 2017;42:2441-2452 \begin{tabular}{l|l|l} 
and Biochemistry Published online: August 21, 2017 & $\begin{array}{l}\text { C) } 2017 \text { The Author(s). Published by S. Karger AG, Basel } \\
\text { www.karger.com/cpb }\end{array}$ \\
\hline
\end{tabular}}

Bai et al.: Effect of Huaier in MsPGN

27 Ikezumi Y, Kanno K, Karasawa T, Han GD, Ito Y, Koike H, Toyabe S, Uchiyama M, Shimizu F, Kawachi H: The role of lymphocytes in the experimental progressive glomerulonephritis. Kidney Int 2004;66:1036-1048.

28 Funk JO, Galloway DA: Inhibiting CDK inhibitors: new lessons from DNA tumor viruses. Trends Biochem Sci 1998;23:337-341.

29 Shankland SJ, Hugo C, Coats SR, Nangaku M, Pichler RH, Gordon KL, Pippin J, Roberts JM, Couser WG, Johnson RJ: Changes in cell-cycle protein expression during experimental mesangial proliferative glomerulonephritis. Kidney Int 1996;50:1230-1239.

30 Bokemeyer D, Panek D, Kitahara M, Trzaskos JM, Müller CE, Hockemeyer J, Kunter U, Boor P, Floege J, Kramer HJ: The map kinase ERK regulates renal activity of cyclin-dependent kinase 2 in experimental glomerulonephritis. Nephrol Dial Transplant 2007;22:3431-3441.

-31 Daniel C, Pippin J, Shankland SJ, Hugo C: The rapamycin derivative RAD inhibits mesangial cell migration through the CDK-inhibitor p27KIP1. Lab Invest 2004;84:588-596.

-32 Daniel C, Duffield J, Brunner T, Steinmann-Niggli K, Lods N, Marti HP: Matrix metalloproteinase inhibitors cause cell cycle arrest and apoptosis in glomerular mesangial cells. J Pharmacol Exp Ther 2001;297:57-68.

-33 Wasser S: Medicinal mushrooms as a source of antitumor and immunomodulating polysaccharides. Appl Microbiol Biotechnol 2002;60:258-274.

34 Li LT, Shi MY, Wei SY, Li T, Li B: Huai Qi Huang ameliorates proteinuria and hematuria in mild IgA nephropathy patients: a prospective randomized controlled study. J Formos Med Assoc 2013;112:766-772.

-35 Zhu C, Huang S, Ding G, Yuan Y, Chen Q, Pan X, Chen R, Zhang A: Protective effects of Huang Qi Huai granules on adriamycin nephrosis in rats. Pediatr Nephrol 2011;26:905-913.

-36 Zhang L, Kong D, Meng H, Han C, Zhu J, Qiao J, He Y, Wang T, Li X, Zhang F: Plasma Gelsolin Promotes Proliferation of Mesangial Cell in IgA Nephropathy. Cell Physiol Biochem 2016;40:1473-1486.

-37 Liang Y, Zhang J, Zhou Y, Xing G, Zhao G, Liu Z: Proliferation and Cytokine Production of Human Mesangial Cells Stimulated by Secretory IgA Isolated from Patients with IgA Nephropathy. Cell Physiol Biochem 2015;36:1793-1808.

-38 Chen L, Lu Y, Wen J, Wang X, Wu L, Wu D, Sun X, Fu B, Yin Z, Jiang H: Comparative Proteomics Analysis of Mouse Habu Nephritis Models with and without Unilateral Nephrectomy. Cell Physiol Biochem 2016;39:1761-1776.

39 Wang D, Guan MP, Zheng ZJ, Li WQ Lyv FP, Pang RY, Xue YM: Transcription Factor Egr1 is Involved in High Glucose-Induced Proliferation and Fibrosis in Rat Glomerular Mesangial Cells. Cell Physiol Biochem 2015;36:2093-2107.

40 Chen YT, Chang FC, Wu CF, Chou YH, Hsu HL, Chiang WC, Shen J, Chen YM, Wu KD, Tsai TJ: Platelet-derived growth factor receptor signaling activates pericyte-myofibroblast transition in obstructive and postischemic kidney fibrosis. Kidney Int 2011;80:1170-1181.

41 Kong F, Ma L, Zou L, Meng K, Ji T, Zhang L, Zhang R, Jiao J: Alpha1-Adrenergic Receptor Activation Stimulates Calcium Entry and Proliferation via TRPC6 Channels in Cultured Human Mesangial Cells. Cell Physiol Biochem 2015;36:1928-1938.

-42 Ostendorf T, van Roeyen CR, Peterson JD, Kunter U, Eitner F, Hamad AJ, Chan G, Jia XC, Macaluso J, GazitBornstein G: A fully human monoclonal antibody (CR002) identifies PDGF-D as a novel mediator of mesangioproliferative glomerulonephritis. J Am Soc Nephrol 2003;14:2237-2247.

43 Hida M, Fujita H, Ishikura K, Omori S, Hoshiya M, Awazu M: Eicosapentaenoic acid inhibits PDGF-induced mitogenesis and cyclin D1 expression via TGF- $\beta$ in mesangial cells. J Cell Physiol 2003;196:293-300.

44 Yan L, Liu X, Yin A, Wei Y, Yang Q, Kong B: Huaier aqueous extract inhibits cervical cancer cell proliferation via JNK/p38 pathway. Int J Oncol 2015;47:1054-1060.

45 Manni I, Tunici P, Cirenei N, Albarosa R, Colombo BM, Roz L, Sacchi A, Piaggio G, Finocchiaro G: Mxi1 inhibits the proliferation of U87 glioma cells through down-regulation of cyclin B1 gene expression. $\mathrm{Br} \mathrm{J}$ Cancer 2002;86:477-484. 